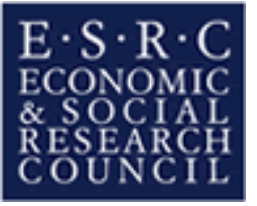

\title{
Waterbed Effects and Buyer Mergers
}

\author{
by
}

\author{
Adrian Majumdar \\ ESRC Centre for Competition Policy \\ University of East Anglia \\ and \\ RBB Economics \\ CCP Working Paper 05-7
}

\begin{abstract}
This paper demonstrates how a profitable, downstream merger can lower the merged entity's input price while raising that of its rivals, leading to an adverse effect on final consumers. This novel 'waterbed' result is surprising and very different to the unilateral and co-ordinated effects usually considered in the analysis of horizontal mergers. When demand is linear, all mergers involving a powerful buyer harm overall welfare even though the merger leads to marginal cost reductions that substantially increase output by the merged entity.
\end{abstract}

June 2005

Keywords: Mergers; Buyer Power; Raising Rivals' Costs.

JEL Classification: L40, D43

Acknowledgments:

I am grateful to Stephen Davies, Morten Hviid and Bruce Lyons for several helpful discussions and comments which have substantially improved the paper. Remaining errors are my own.

Contact details:

adrian.majumdar@ rbbecon.com

ISSN 1745-9648 


\section{Waterbed effects, countervailing buyer power and buyer mergers.}

\section{Introduction}

\subsection{Waterbed effects}

Can a merger of two buyers lower the merged entity's input price while raising that of its rivals as suppliers make up their lost margins from weaker buyers? An economist's first instinct is usually to answer: 'No! If suppliers could raise prices elsewhere, why are they not already doing it?'

Nevertheless, this 'waterbed' effect has influenced policy makers in two recent mergers. The United Kingdom Competition Commission (CC), during an investigation of several prospective supermarket mergers, states: 'The exercise of buyer power by the merged entity would have adverse effects on other, smaller, grocery retailers through the "waterbed" effect - that is, suppliers having to charge more to smaller customers if large retailers force through price reductions which would otherwise leave suppliers insufficiently profitable' (CC (2003) paragraph 2.218). The $\mathrm{CC}$ also considered that a similar effect might occur as a result of a merger in the private health care market (CC (2000) paragraph $2.180 \mathrm{~b}$ ).

The motivation for this paper is to establish conditions in which a merger gives rise to such a waterbed effect and to examine the implications for welfare. To my knowledge, this is the first paper to address the issue. ${ }^{1}$ In related papers, Matthewson and Winter (1996) and Gans and King (2002) demonstrate how the introduction of buyer power (modelled by a first mover advantage in dealing with suppliers) can benefit the powerful buyer while leaving other buyers worse off. However, these authors do not address the specific issue of how pre-existing buyer power may be enhanced by a merger with adverse effects for final consumers in a downstream market (see section 5 for a further discussion).

I consider a setting where there is a single procurement market upstream and several 'local' Cournot markets downstream. In the procurement market a powerful buyer, R, contracts directly with its suppliers. Then, other buyers purchase inputs on a spot market. I consider R's incentive to purchase stores in local markets where it does not already have a presence. This allows me to concentrate on mergers that leave the local market structure unchanged. The merger is nevertheless a horizontal merger in the sense that it is a merger of two buyers in the procurement market.

I find that a buyer merger typically reduces welfare. This is a novel theory of how a merger may harm consumers. Even though the merged firm increases output compared to pre-merger levels, output declines overall (i.e. aggregated across local markets) due to the higher input price that rivals face. This model therefore differs significantly from the class of mergers analysed by Farrell and Shapiro (1990). In their paper, if a merger of Cournot firms generates synergies which induce the merged

\footnotetext{
1 This paper is concerned only with a waterbed effect arising from a merger of two single product firms. The term waterbed effect has also been used in relation to multiproduct firms where price caps are imposed. Broadly speaking, the idea is that if a multiproduct firm is subject to a break even constraints (e.g. due to rate of return regulation or due to intense competition from other similar firms) then capping the price on one line of business may lead to a price rise on another line of business.
} 
entity to increase output (compared to the sum of the pre-merger outputs of the merging firms) this is sufficient for welfare to increase. With the waterbed effect described in this paper, however, a rise in the merged entity's output is not sufficient to improve welfare.

The waterbed effect arises from two features. First, the merger allows the target store to benefit from the lower prices negotiated by the powerful buyer. Second, the merger reduces demand from independent stores that purchase in the spot market. The fall in their demand weakens the constraint provided by a potential entrant to the spot market, as that entrant would have to charge a higher price to recover its entry costs.

The waterbed effect also provides a different angle on raising rivals' costs. In this literature, harm to competition may arise where a dominant firm profits from raising its own costs because this raises rivals' costs by sufficiently more as set out in the seminal paper by Salop and Scheffman (1983). However, as Mason (2002) notes, cost raising strategies usually require strong restrictions on parameters if they are to be profitable. This is because the direct effect on profits is negative (own costs go up) and this must be outweighed by a very strong indirect effect (i.e. that arising from rivals having higher costs). ${ }^{2}$ In general, it is difficult to find 'costless' cost raising strategies. With the waterbed effect, however, raising rivals' costs by merger is profitable because it is accompanied by a reduction in own costs. Even absent the cost raising effect, the merger would be profitable.

The rest of the paper is set out as follows. In section 2, we set out the model. Section 3 then addresses welfare implications of a merger. Section 4 discusses the robustness and realism of the key assumptions in the paper. Section 5 compares and contrasts the results to previous literature on buyer power and buyer mergers. Finally, section 6 offers concluding remarks and policy implications.

\section{The model}

\subsection{Assumptions}

There are two identical manufacturers, $\mathrm{M}_{1}$ and $\mathrm{M}_{2}$. In order to produce, each supplier must sink a fixed cost, $F>0 . F$ is assumed to be sufficiently low to allow at least one manufacturer profitably to supply buyers (the specific condition is set out below in section 2.2). Having sunk $F$, manufacturers can produce an identical input at a constant marginal cost, equal to zero.

Manufacturers sell to retailers in a procurement market. Retailer $\mathrm{R}$ has a first mover advantage in dealing with manufacturers which means that manufacturers establish R's input price before they make offers to other retailers (timing assumptions are described in detail in the following section). $\mathrm{R}$ may own more than one store provided that it does not own two or more stores in the same local market. Other retailers, which we also refer to as 'independents', own only one store each.

\footnotetext{
${ }^{2}$ Mason (2002) focuses on the other strand in the raising rivals' costs literature that firms might raise each other's costs in order to dampen competition.
} 
There are $m$ separate 'local' retail markets, where $m \geq 2$. Each local market potentially has $n$ identical retail stores, where $n \geq 2$. Stores in each local market are Cournot competitors. Each local market faces the same market inverse demand form, $\mathrm{P}(\mathrm{Q})$, where $\mathrm{P}(\mathrm{Q})<0$ and $\mathrm{P}^{\prime}(\mathrm{Q}) \leq 0$. All assumptions are common knowledge.

\subsubsection{Timing assumptions}

Stage 1 - retail merger

- $\mathrm{R}$, which begins the game owning one store, purchases stores in as many local markets as it wishes provided that $\mathrm{R}$ does not own more than one store in any local market. We denote the number of stores owned by $\mathrm{R}$ at the end of stage 1 by $r$, where $1 \leq r \leq m$.

Stage 2 -invitation to tender

- $\mathrm{R}$ invites manufacturers to bid for the right to be its sole input supplier.

- Manufacturers place bids simultaneously by means of a sealed bid auction. Bids specify the input price at which $\mathrm{R}$ may purchase whatever amount it desires.

- $\mathrm{R}$ appoints a manufacturer and that manufacturer commits to producing by sinking $F$. R's decision to appoint a manufacturer and that manufacturer's commitment to production are public knowledge. R may decline both offers if neither would be profitable.

Stage 3 - spot market price setting

- Each manufacturer simultaneously announces a price at which it is willing to supply the remaining retailers. We denote this the spot market price, $s_{i}(i=1,2) ; s_{i}$ is observed by all players.

Stage 4 - procurement orders

- All retailers simultaneously and non-cooperatively place orders with manufacturers. They incur a small, fixed transaction cost per order.

- Manufacturers supply spot market purchasers provided that their continuation profits are non-negative. If a manufacturer's continuation profits are negative, it withdraws its spot market offer. If one manufacturer withdraws its offer while the other does not, retailers that had ordered from the former are given the opportunity to purchase from the latter at the latter's spot market price. If both manufacturers withdraw offers, spot market buyers are not supplied the input.

Stage 5 - retail competition

- Retailers transform their inputs into the final product at zero cost. One unit of input is required to produce each unit of output.

- Retailers are Cournot competitors in each local market.

The robustness and realism of the key assumptions are discussed in section 4 .

\subsection{Results for stages 2 to 5 .}

First we solve the game for stages 2 to 5, taking the number of stores owned by $\mathrm{R}$ as given (we consider stage 1 , the incentive to merge, in section 2.3). We proceed by 
backwards induction. Rather than set out all definitions up front, we introduce them as we proceed so as to provide context to the particular variables defined.

\section{Stage 5 - retail competition}

At stage 5, each local market is characterised by Cournot competition among active retailers. We define the following outputs:

- $\quad \mathrm{q}_{\mathrm{Rj}}\left(c, s, a_{j}\right)$, output by an active store owned by $\mathrm{R}$ in market $j$;

- $\mathrm{q}_{\mathrm{LRj}}\left(c, s, a_{j}\right)$, output by an active independent store that competes in a local market $j$, where $\mathrm{R}$ also has an active store;

- $\mathrm{q}_{\mathrm{Lk}}\left(s, a_{k}\right)$ output by an active independent store that competes in a local market $k$, where $\mathrm{R}$ does not have an active store,

where $c$ refers to R's input price, $s$ the spot market price, and $a_{j}$ and $a_{k}$ the number of active stores in a given local market $\left(a_{j} \leq n, a_{k} \leq n\right)$. Output and profit at each store are decreasing in the store's input price and increasing in the input price paid by other stores that compete in the same local market.

Define $\mathrm{Q}_{\mathrm{s}}(c, s, \boldsymbol{a})$ to be total output by independent stores and $\mathrm{Q}_{\mathrm{R}}(c, s, \boldsymbol{a})$ to be $\mathrm{R}$ 's total output, where $\boldsymbol{a}$ stands for the relevant ' $a_{j}$ ' and ' $a_{k}$ ' variables. (It turns out that all firms will be active in equilibrium.)

Since each local Cournot market is characterised by constant marginal costs and (quasi) concave demand, this is sufficient for the stage 5 equilibrium to be unique. ${ }^{3}$

\section{Stage 4- procurement orders}

We now consider orders placed with manufacturers. Given that R does not decline both offers at stage 2, we may assume without loss of generality that $\mathrm{R}$ chooses to deal with $\mathrm{M}_{1}$. At stage 4 , therefore, $\mathrm{M}_{1}$ will have already sunk $F$, and so its continuation profit from supplying spot market purchasers is non-negative provided its spot market offer, $s_{1}$ is also non-negative.

On the other hand, $\mathrm{M}_{2}$ has not yet sunk $F$. Thus its continuation profit is positive if and only if:

$$
\mu s \mathrm{Q}_{\mathrm{S}}(c, s, \boldsymbol{a}) \geq F,
$$

where $s \mathrm{Q}_{\mathrm{S}}(c, s, \boldsymbol{a})$ is the total revenue available from spot market sales and $\mu$ is $\mathrm{M}_{2}$ 's share of those sales. Equation [1] is $\mathrm{M}_{2}$ 's participation condition.

If manufacturers announce different (non-negative) prices, all spot market buyers purchase from the lowest priced manufacturer provided that this would allow that manufacturer to make non-negative continuation profits. More formally, denote $\mathrm{M}_{2}$ 's spot market offer $s_{2}$. If $s_{1}<s_{2}$, spot market purchasers will place orders only with $\mathrm{M}_{1}$ (provided that they expect $\mathrm{M}_{1}$ to meet its participation condition, i.e. provided $s_{1} \geq$

\footnotetext{
${ }^{3}$ See Farrell and Shapiro (1990) equations (3) and (4).
} 
$0^{4}$ ). Likewise, if $s_{2}<s_{1}$, spot market purchasers place orders only with $\mathrm{M}_{2}$ (i.e. $\mu=1$ ), given that such orders are expected to allow $\mathrm{M}_{2}$ to meet its participation condition. ${ }^{5}$

An interesting issue is what happens if manufacturers announce the same spot market price, i.e. $s_{1}=s_{2}$. Consider one possibility which we will make use of in our discussion of stage 3. Suppose that the only way for $\mathrm{M}_{2}$ to meet its participation condition is to supply all spot market purchasers. In this case, all it takes is for one buyer to purchase from $\mathrm{M}_{1}$ in order for $\mathrm{M}_{2}$ to withdraw its offer. As a result, buyers that originally ordered from $\mathrm{M}_{2}$ would still have the opportunity to purchase at price $s_{2}$ (since they can purchase from $\mathrm{M}_{1}$ at $s_{1}$ and $s_{1}=s_{2}$ ), but they would incur a second (small) transaction cost of ordering from $\mathrm{M}_{1}$. Thus, spot market buyers would have a weakly dominant strategy of placing orders with $\mathrm{M}_{1}$ in the first instance as this ensures they pay the transaction cost only once. ${ }^{6}$

\section{Stage 3 - spot market price setting}

At stage 3, spot market prices are announced simultaneously. To keep stage 3 interesting, we make two minor assumptions. First assume that spot market demand is inelastic over the range $\left(0, s^{\max }\right)$, where $s^{\max } \equiv \arg \max s \mathrm{Q}_{\mathrm{S}}(c, s, \boldsymbol{a})$. In other words, $s^{\max }$ is the spot market price which maximises spot market revenue. Second, assume that the fixed cost, $F$, is sufficiently low so that a spot market price always exists which is less than $s^{\max }$ and which generates spot market revenue at least as high as $F$.

Consider the lowest possible price that $\mathrm{M}_{2}$ could announce that is a candidate for meeting its participation condition [1]. This price, $s^{b}$, is the lowest value for $s$ that satisfies the following condition: ${ }^{7}$

$$
s \mathrm{Q}_{\mathrm{S}}(c, s, \boldsymbol{a})=F
$$

Suppose $\mathrm{M}_{2}$ offers $s^{b}$ and consider $\mathrm{M}_{1}$ 's possible best responses. Since $s^{b}>0, \mathrm{M}_{1}$ 's best response is to offer the same price. ${ }^{8}$ Buyers will then purchase from $\mathrm{M}_{1}$ as this is their weakly dominant strategy, as explained in the previous subsection. Offering a

\footnotetext{
${ }^{4}$ It would not be rational for a retailer to order from a manufacturer that was not expected to deliver on that order since that retailer would incur a transaction cost without expecting to obtain supplies.

${ }^{5}$ This statement is not quite as straightforward as it may first appear. Suppose that the only way for $\mathrm{M}_{2}$ to meet its participation condition is to supply all spot market purchasers. In this case, even though $s_{1}$ $>s_{2}$, a buyer might conceivably purchase from $\mathrm{M}_{1}$ and thereby ensure that any active retailer that purchases on the spot market must also pay the higher input price, $s_{1}$. This might be profitable if some buyers were expected to order from $\mathrm{M}_{2}$ and, as a result of $\mathrm{M}_{2}$ withdrawing its offer, these buyers would remain inactive rather than incur the second transaction cost required to order from $\mathrm{M}_{1}$. We rule out this possibility by assuming that the fixed transaction cost incurred per order is very small. We also assume that if all buyers pay the same input price, their profits are decreasing in that price. This ensures that if $s_{1}>s_{2}$ a buyer would not find it profitable to purchase from $\mathrm{M}_{1}$ to ensure that all other spot market buyers paid the higher price as well.

${ }^{6}$ The assumption that buyers that originally order from $\mathrm{M}_{2}$ would have the opportunity (for a small transaction cost) to purchase at price $s_{1}$ if $\mathrm{M}_{2}$ withdraws its offer is not essential. Instead, we might note that if $s_{1}=s_{2}=s^{b}$, buyers naturally purchase from $\mathrm{M}_{1}$ as to purchase from $\mathrm{M}_{2}$ would not be rational if there is a small chance that one buyer 'trembles' and erroneously purchases from $\mathrm{M}_{1}$.

${ }^{7}$ Note that, for sufficiently low values of $F$, there will typically be two input prices that satisfy this condition. If so, only the lowest price is relevant. If one manufacturer charged a higher price that satisfied [2], the other could profitably undercut.

${ }^{8}$ Provided that $c \geq 0$. If $c<0$ (which will not occur in equilibrium), $\mathrm{M}_{1}$ may have an incentive to bid below $s^{b}$ to shift sales away from $\mathrm{R}$ where it makes a loss in the continuation game.
} 
higher price would forfeit profitable sales to $\mathrm{M}_{2}$ while offering a lower price would not be as profitable as offering $s^{b}$.

What price will $\mathrm{M}_{2}$ offer? If it offers any price $s^{\prime}$ in the range $s^{b}<s^{\prime}<s^{\max }, \mathrm{M}_{1}$ 's best response is to offer $s^{\prime}-\varepsilon$, where $\varepsilon$ is an arbitrarily small amount. However, if $\mathrm{M}_{1}$ were to offer $s^{\prime}-\varepsilon, \mathrm{M}_{2}$ would find it profitable to undercut for any $s^{\prime}-\varepsilon>s^{b}$. Therefore, equilibrium occurs only when $\mathrm{M}_{1}$ and $\mathrm{M}_{2}$ both announce a price of $s^{b}$.

It follows that in equilibrium all spot market buyers purchase from $\mathrm{M}_{1}$ and $\mathrm{M}_{1}$ earns a continuation profit equal to $F . \mathrm{M}_{2}$ receives no orders and earns its outside option, zero.

\section{Stage 2 - invitation to tender}

Our discussion of stages 3 and 4 demonstrates that R's supplier is assured of covering its fixed costs while the other supplier earns zero. Stage 2 is therefore straightforward. Intense competition among suppliers (resulting from the sealed bid auction to be R's only supplier) induces both suppliers to offer an input price, $c$, equal to zero. $\mathrm{R}$ then arbitrarily chooses a supplier. For convenience, we have adopted the convention that $\mathrm{R}$ deals with $\mathrm{M}_{1}$.

Even though $\mathrm{M}_{1}$ makes no revenues from sales to $\mathrm{R}$, it is rational to sink $F$ during stage 2 because $M_{1}$ knows that it will recover its fixed cost at stage 4 and break even overall.

\section{Interim summary}

So far we have shown that $R$ deals with $M_{1}$ and obtains its input at a price zero. $M_{1}$ sells to all remaining stores who purchase on the spot market at $s^{b}$. It follows that all stores are active in the downstream market (i.e. in equilibrium, $a_{j}=a_{k}=n$ for all $j$ and k). ${ }^{9}$

\subsection{Stage 1 - incentives to merge and the waterbed effect}

We now turn to stage 1 and consider R's incentives to merge (i.e. we allow $r$ to vary). First we establish a lemma that any merger leads to an increase in the spot market price. Second we establish a lemma that successive mergers are profitable. Finally, we establish our first proposition - the existence of a waterbed effect.

Lemma 1: As the number of stores owned by $\mathrm{R}$ increases, the spot market price goes up.

Before proving this lemma, it is helpful to define the following terms. Consider store level demand. In any of the $r$ markets where R operates, output by each of R's stores is the same; we denote this $\mathrm{q}_{\mathrm{R}}\left(s^{b}(r)\right) .{ }^{10}$ In each of the markets where $\mathrm{R}$ sells, there will be $(n-1)$ identical independent stores; we denote an individual store's output as

\footnotetext{
${ }^{9}$ Since $n$ is finite, the Cournot equilibrium is such that each firm receives a price above its unit input cost. Thus $\mathrm{R}$ and the other stores all make positive profits which by assumption exceed the only fixed cost that they face (i.e. the small transaction cost of dealing with $\mathrm{M}_{1}$ ).

${ }^{10}$ Our previous discussion solved stages 2 to 5 of the game for a given value of $r$ in the range $1 \leq r \leq m$. We now introduce $r$ as an argument to our solution prices and quantities (we drop $c$ as an argument since $c=0$ in equilibrium).
} 
$\mathrm{q}_{\mathrm{LR}}\left(s^{b}(r)\right)$. In each of the remaining $(m-r)$ markets, there will be $n$ identical independent stores; we denote an individual store's output as $\mathrm{q}_{\mathrm{L}}\left(s^{b}(r)\right)$.

It follows that spot market demand is:

$$
\mathrm{Q}_{\mathrm{S}}\left(s^{b}(r)\right)=(m-r) n \mathrm{q}_{\mathrm{L}}\left(s^{b}(r)\right)+r(n-1) \mathrm{q}_{\mathrm{LR}}\left(s^{b}(r)\right)
$$

We now prove that the derivative of $s^{b}(r)$ with respect to $r$ is positive in the range $1 \leq$ $r \leq m$.

Proof. From [2] and [3]:

$$
s^{b}(r)\left\{(m-r) n \mathrm{q}_{\mathrm{L}}\left(s^{b}(r)\right)+r(n-1) \mathrm{q}_{\mathrm{LR}}\left(s^{b}(r)\right)\right\}-F=0
$$

Denote equation [4] as $\mathrm{f}\left(s^{\mathrm{b}}(r)\right)$. By the implicit function rule:

$$
\mathrm{d} s^{b}(r) / \mathrm{d} r=-\delta \mathrm{f}\left(s^{b}(r)\right) / \delta r / \delta \mathrm{f}\left(s^{b}(r)\right) / \delta s^{b}(r) .
$$

The numerator of [5] equals:

$$
-s^{b}(r)\left\{-n \mathrm{q}_{\mathrm{L}}\left(s^{b}(r)\right)+(n-1) \mathrm{q}_{\mathrm{LR}}\left(s^{b}(r)\right)\right\}
$$

and is positive since $\mathrm{q}_{\mathrm{L}}\left(s^{b}(r)\right)>\mathrm{q}_{\mathrm{LR}}\left(s^{b}(r)\right)$.

The denominator of [5] equals:

$$
\left(1-\eta\left(s^{b}(r)\right)\right) \mathrm{Q}_{\mathrm{S}}\left(s^{b}(r)\right)
$$

where $\eta\left(s^{b}(r)\right)$ is the absolute value of the elasticity of spot market demand evaluated at $s^{b}(r)$. We made the minor assumption that $0<\eta\left(s^{b}(r)\right)<1$ (see the discussion of stage 3 above and note that this assumption is not required if local demand is linear) and hence the denominator is positive. Thus the sign of [5] is positive. $Q E D$.

There is an intuitive explanation for why $s^{b}(r)$ increases with $r$. Recall that the spot market price must generate revenues equal to the fixed cost, $F$. As $\mathrm{R}$ owns more stores there are fewer independent stores over which $F$ can be spread out. Thus, each independent store must pay a higher input price. Moreover, as independent stores pay a higher price, their input demands decline. Thus, $F$ is recovered not only over fewer stores but also each store purchases a smaller quantity. Both effects work to push up $s^{b}(r)$.

Lemma 2: Each successive merger is increasingly profitable for $\mathrm{R}$ (up to the point where further mergers are not permitted).

Proof. Consider what happens when R purchases one extra store (a 'target' store) in a 'target' market. By purchasing the target store, that store's input price falls from the spot market price to zero and so, in this sense, R's input price falls in the target market. R's input price in all the other stores it owns remains unchanged (at zero). 
Profit earned at the target store increases since the store's input price falls while, from lemma 1, the input price of its rivals goes up. Profit earned at R's other stores also increases since they compete with higher cost rivals.

All of R's stores earn identical profits. Since the profit of a store that R already increases as $\mathrm{R}$ purchases another store, it must be the case that R's profits are increasing in $r$. This means that at stage $1, \mathrm{R}$ purchases stores in every market where it did not previously have a store. In other words, $\mathrm{R}$ purchases $m-1$ stores in order to have a presence in all local markets and so stage 2 commences with $r=m$. QED.

Proposition 1: A 'waterbed effect' exists. As $\mathrm{R}$ extends its buyer power by a profitable merger (here modelled by an increase in $r$ in the range $1 \leq r \leq m$ ), R's input price falls in the target market and remains unchanged elsewhere, while its rivals' input price increases.

Proof. This follows from lemmas 1 and 2 above.

\section{Welfare effects of the merger}

In this section we consider how a merger affects overall welfare which we define as the sum of consumer and producer surplus. We denote overall welfare as W(r). First we demonstrate that with linear demand mergers always harm overall welfare, even though the output of the merged firm increases substantially. Second we test the robustness of this finding to an alternative demand specification. Finally, we explain the novelty of our result and compare our findings with the seminal paper on Cournot mergers by Farrell and Shapiro (1990).

\subsection{Linear demand}

Overall welfare is the sum of welfare in each local market. The contribution to overall welfare from any particular local market increases with output in that market. ${ }^{11}$ When $\mathrm{R}$ purchases a store in a target market, the change in total welfare can be broken down into the three following effects. First, output must fall in any local market where R has no presence (since $s^{b}(r)$ rises). Second, output must fall in any market where R already had a presence ( since $^{b}(r)$ rises while R's input price remains unchanged). Both these effects are bad for welfare.

However, the third effect - in the target market - is ambiguous. The target store faces a lower input price while other stores have a higher input price. Therefore, if the raising rivals' cost effect is relatively weak, output may increase in the target market.

It turns out that with linear demand, any increase in welfare in the target market does not offset the decrease in welfare in other markets. This is our second proposition.

\footnotetext{
${ }^{11}$ Farrell and Shapiro (1990) note that in a Cournot market welfare may increase even though output declines due to output being shifted from high cost firms to low cost firms. However, in our model this does not apply. The marginal cost of interest for overall welfare is $\mathbf{M}_{1}$ 's marginal cost of production which is zero. Therefore, welfare in any local market is simply the area under the demand curve between the origin and the level of local output.
} 


\section{Proposition 2: When local demand is linear, welfare always declines as a result of the merger (i.e. $\mathrm{dW}(r) / \mathrm{d} r<0)$.}

Proof. See appendix.

This is a striking result. For a commonly used demand form, any merger is harmful even though it generates efficiencies for the merged entity (i.e. a substantial fall in marginal cost for R's store in the target market). We discuss this further below.

\subsection{Concave demand}

In this section we discuss welfare effects more generally.

We explain in the appendix that if the merger leads to a rise in the sum of marginal costs in the target market, this is sufficient (but not necessary) for overall welfare to fall. Formally, if [8] holds, overall welfare must fall because output falls in all markets, including the target market (see lemma 3 ).

$$
(n-1) \mathrm{d} s^{b}(r) / \mathrm{d} r>s^{b}(r)
$$

In other words, if the raising rivals' cost effect is strong enough, the increase in the input price paid by independent stores will be so great that output will fall in that market despite the fall in R's costs.

Further, we show in the appendix that the more stores that R owns in the first place, the higher the likelihood that purchasing one more store will harm overall welfare (see lemma 4). Intuitively, if $F$ is spread over several independents then the loss of one independent is hardly noticeable. However, if $F$ is spread over relatively few independents, then the loss of one more independent has a marked effect on the rest. So, the more stores that R owns (and hence the fewer independents there are), the greater is the raising rivals' cost effect and the more likely that a merger will lead to a reduction in output in the target market.

Interestingly, from lemma 2 we know that the incremental profit from purchasing an additional store is also increasing in $r$. Therefore, R's strongest incentive to merge occurs when $r$ is 'high', that is when the merger has the greatest harm (or smallest benefit) for welfare.

Finally, we consider the following form of concave demand as a robustness check.

$$
\mathrm{P}(s(r))=a-b \mathrm{Q}(s(r))^{k}
$$

We show that, with this form of demand, welfare is higher when $r$ equals zero (i.e. all purchases are made on the spot market), than when $r$ equals $m$ (i.e. $\mathrm{R}$ has a presence in all local markets). It follows that even if a merger increases welfare to start off with, there must come a point when the merger starts to harm welfare. Once we reach this point, welfare falls for any further mergers (see proposition 3). Our suspicion is that welfare declines with any merger although we have not proved this. 


\subsection{A novel result}

Our model provides an important result. For many possible forms of (quasi) concave local demand, a profitable merger that induces the merged entity to increase output may reduce welfare. At best, when $\mathrm{R}$ purchases an additional store the merger benefits consumers only in the target market. Consumers in other markets pay higher prices. At worst, when [8] holds (which is more likely when R already owns many stores), all consumers pay higher prices.

The latter finding is particularly interesting because it departs significantly from the traditional view of horizontal mergers. The analysis of horizontal mergers is usually concerned with 'unilateral' (or equivalently 'non-coordinated') effects and coordinated effects. In the former case, the potential concern is that the reduction in concentration will provide the merged entity with an incentive to restrict output. Unless efficiencies are particularly strong, the merger moves the market to a higher priced equilibrium. In the latter case, the concern is that the merger makes tacit collusion more likely or strengthens existing tacit collusion.

In our paper, the merger generates efficiencies and induces the merged firm to increase output to a level that exceeds the sum of the pre merger output of its component stores. In the Cournot models considered in the seminal paper by Farrell and Shapiro (1990), this would be sufficient to increase welfare in the target market. However, unlike those authors, we also have a raising rivals' cost effect due to the reduction of spot market demand. This is sufficient to reduce welfare in the target market when [8] holds.

In sum, our harm to consumers arises solely from a buyer power effect in the procurement market. The merger would be profitable even absent the raising rival's costs effect but, because of that effect, welfare is harmed. The harm to consumers does not arise from unilateral or co-ordinated effects because we leave both the local market structure and the form of competitive interaction unchanged. This, to the author's knowledge, is a new theory of harm from a horizontal merger.

\section{Discussion of key assumptions}

In this section, we discuss the robustness of the model's key assumptions and in which situations the model may have practical relevance. We demonstrate that the intuitions from the model apply more widely than in the specific setting described in the preceding sections.

At stage 2 (invitation to tender), $\mathrm{R}$ derives its buyer power from two features. First, it has the ability to have suppliers compete at a sealed bid auction (where the two suppliers have full information and common valuation) for the right to be its sole input supplier. Costs of making a bid are assumed to be zero. Under these assumptions we have a standard Bertrand competition among identical suppliers of homogenous goods.

Our stage 2 results are most likely to be relevant where suppliers are similar and have both a good knowledge of each other's costs and a reasonable idea of the value of the 
'prize' (i.e. the continuation profit available in the spot market). ${ }^{12}$ Interestingly, this suggests that stage 2 of the model is less likely to apply to branded goods (in contrast to the view put forward by CC (2003)) and perhaps more likely to apply to suppliers of own label products. ${ }^{13}$

The second feature at the invitation to tender stage is R's first mover advantage; $\mathrm{R}$ deals with suppliers before other buyers. ${ }^{14}$ This begs the question: why might $\mathrm{R}$ have first mover advantage? We might justify R's first mover advantage by assuming that $\mathrm{R}$ already is large in relation to the purchasing market and that only $\mathrm{R}$ can profitably contract outside the spot market due, say, to economies of scale in striking these contracts. $^{15}$

$\mathrm{R}$ could be large in relation to the purchasing market for one or more of the following reasons:

- R owns many stores instead of just one store. (We assumed that R owned only one store at the start of the game; however, if $\mathrm{R}$ owned more than one store the results are unchanged provided there remains scope for $\mathrm{R}$ to purchase more stores, i.e. $r<m$.);

- $\mathrm{R}$ purchases the input for use in another area (where it does not compete with independents) and so already has dealings with the two suppliers; ${ }^{16}$

- in the downstream market, there is an additional, constant per unit cost of transforming inputs to outputs and that $\mathrm{R}$ has a significantly lower marginal cost of transformation than other stores;

- $\mathrm{R}$ and $\mathrm{M}_{1}$ are vertically integrated.

Any of the above assumptions can be added to the model without qualitatively affecting the results.

A chain store that purchases on a national market but sells into a local market may fit some of the above possibilities. (Note that the model need not be restricted to a single chain. In principle, other chain stores could exist without necessarily affecting the qualitative results of the model. ${ }^{17}$ )

\footnotetext{
${ }^{12}$ Many procurement markets have a bidding process, although not all would necessarily satisfy the conditions for Bertrand competition (see Klemperer (2005)).

${ }^{13}$ An alternative interpretation of stage 2 is as follows. Suppose that prior to the game $\mathrm{M}_{1}$ and $\mathrm{M}_{2}$ already supply the procurement market but at a very high constant marginal cost. $F$ could be the expenditure required to make a major innovation (e.g. an investment in a state of the art distribution system) that substantially reduces the marginal cost of supplying that procurement market (here, to zero).

${ }^{14} \mathrm{R}$ 's first mover advantage is not essential. Suppliers could simultaneously announce prices to $\mathrm{R}$ and to the spot market without affecting the results, provided that $\mathrm{R}$ announces with whom it will deal and that supplier commits to producing before purchase decisions are made (this ensures that all spot market buyers purchase from the same supplier). In this case it is R's ability to deal with suppliers on an individual basis that matters.

${ }^{15}$ Stages 2 and 3 of our model are similar to the game modelled in Gans and King (2002). The latter assume that small buyers are not sufficiently large to contract with.

${ }^{16}$ For example, suppose $\mathrm{M}_{1}$ and $\mathrm{M}_{2}$ produce an identical own label product and also (potentially) supply the own label product to the spot market. These suppliers may also produce a branded product which they distribute through R (and so R would already have dealings with these suppliers).

${ }^{17}$ For example, there could be other powerful chain stores that compete in the downstream market but have alternative suppliers that are contracted not to supply other buyers (and so cannot supply the spot market). They would not directly be affected by the change to the procurement market (but they may
} 
The fundamental assumption that drives this model is that reducing spot market demand leads to a higher spot price being established at stage 3. In this model, taking a potential buyer out of the spot market means that fixed costs must be recovered over fewer sales and so the spot market prices rise. This effect is driven by what amounts to a contestable spot market. Although $\mathrm{M}_{1}$ has already sunk the fixed cost required to produce, if $\mathrm{M}_{1}$ attempts to earn continuation profits that exceed $F$ at stage $3, \mathrm{M}_{2}$ can undercut by offering a break even price, $\mathrm{s}^{\mathrm{b}}(r)$, and thereby win all spot market buyers. However, as $\mathrm{R}$ purchases more stores, the pool of buyers available for $\mathrm{M}_{2}$ declines and so $\mathrm{s}^{\mathrm{b}}(r)$ increases $-\mathrm{M}_{2}$ has fewer buyers over which to spread its fixed costs. ${ }^{18}$

Given the Bertrand competition at stage 2 (invitation to tender), it is reasonable to assume a 'contestable' spot market. That is, having assumed similarity of suppliers, common knowledge of costs and absence of costs of making a bid at the tendering stage with $\mathrm{R}$, the Bertrand spot market is the natural way to model competition for the remaining buyers (which, by assumption, are too small to contract with on an individual basis).

We could generate the waterbed effect in alternative ways. For example, if average costs decline with output up to a point, similar qualitative results can be derived. ${ }^{19}$ Intuitively, where the merger reduces spot market demand sufficiently to prevent $\mathrm{M}_{2}$ supplying the spot market at an efficient scale, $\mathbf{M}_{2}$ becomes a weaker constraint on $\mathbf{M}_{1}$ and a waterbed effect arises which may reduce welfare.

Finally, we have assumed that supplier-retailer contracts specify an input price only. At stage 2 (invitation to tender) nothing turns on this. If $\mathrm{M}_{1}$ were to offer a combination of a fixed fee and a price at which $\mathrm{R}$ could purchase unlimited quantities of the input, the best offer it could make is, in effect, the same. $\mathrm{M}_{1}$ would not require a fixed payment and would offer the input at marginal cost (i.e. zero). ${ }^{20}$

What is important (but not essential ${ }^{21}$ ), however, is that at stage 3 the spot market specifies only the input price. This ensures that as spot market demand shrinks, $F$ is recovered by a higher spot price as opposed to higher fixed fees for spot market buyers. This can be thought of as a stylised representation of supplier-buyer deals

gain indirectly to the extent that independent stores face higher prices in the local markets where they compete). Alternatively, there could be chain stores that buy on the spot market but which are not large enough to strike deals with suppliers outside of the spot market.

${ }^{18}$ In principle, $\mathrm{M}_{1}$ does not need to sink $F$ at stage 2 (invitation to tender) if its commitment to production can be made in another way (e.g. through a penalty clause that if it fails to supply $\mathrm{R}$ then it must pay a cost in excess of $F$.

${ }^{19}$ This type of cost function was popularised in Rasumsen, Ramseyer and Wiley (1991) and used, for example, in Gans and King (2002).

${ }^{20} \mathrm{We}$ would not expect $\mathrm{M}_{1}$ to offer an input price below zero in return for a fixed fee. This is because in the continuation game, $\mathrm{M}_{1}$ would have the incentive to lower the spot market price below $s^{b}$ to reduce its loss making sales made to $R$.

${ }^{21}$ If we allowed for fixed fees then we might still obtain a reduction in welfare as follows. Suppose that spot market buyers reimburse $\mathrm{M}_{1}$ by means of a fixed fee. Suppose also that spot market buyers are identical other than that they face an additional fixed cost of production in the downstream market which varies among individual stores. As the spot market payment increases (i.e. the fixed fee goes up), this could lead some individual stores to exit the downstream market. The higher concentration would then lead to consumers paying higher prices in some local markets. 
where, even if fixed transfers take place, the input price is by far the key parameter in determining each party's payment.

\section{Discussion of related literature}

\subsection{Buyer power}

Regarding the modelling of buyer power, Gans and King (2002) and, to a lesser degree, Matthewson and Winter (1996) are the papers most closely related to this one. Both papers show how the buyer's first mover advantage allows the buyer to obtain better terms than the remaining buyers.

The stage 2 and 3 timing assumptions in this paper (invitation to tender and spot market pricing) draw closely on Gans and King (2002). These authors consider how exclusionary contracts between a large buyer (or a group of large buyers acting as one) and a supplier can be socially sub-optimal. In their model, the large buyer has a first mover advantage in striking a two-part tariff contract with one or both of two identical suppliers. Having dealt with the large buyer, suppliers then make offers to 'small' buyers on a spot market.

Gans and King (2002) assume that suppliers have average costs that fall with output up to a critical point $\mathrm{Q}^{*}$ after which they are constant and equal to $\mathrm{c}\left(\mathrm{Q}^{*}\right)$. They also assume that demand from the spot market is insufficient to allow a supplier to sell $\mathrm{Q}^{*}$ units at a price of $c\left(Q^{*}\right)$ and that the large buyer purchases sufficiently more than $\mathrm{Q}^{*}$ units when its input price is $c\left(Q^{*}\right)$. In this case, if the large buyer deals exclusively with one supplier there are two effects. First, the 'contracting' supplier achieves its efficient scale. Second, the other supplier is a weaker force in the spot market since it cannot achieve its efficient scale. This raises the equilibrium spot market price and harms welfare. ${ }^{22}$

Matthewson and Winter (1996) put forward the idea that providing a buyer with first mover advantage can both lower that buyer's costs and raise prices for other buyers. In their model, an 'inside' group of buyers is able to form a coalition which makes a take-it-or-leave-it offer to a subset of the population of suppliers. Only this subset of suppliers is active in the next stage, where there is monopolistic competition to supply outsiders (i.e. those not in the buying group). Suppliers are symmetric in that they all charge the same price to outsiders. By restricting the number of active suppliers, the buying group weakens competition to supply outsiders and thereby raises the price that outsiders pay. As a result of outsiders paying more, insiders are able to demand a lower price while allowing suppliers to break even. Matthewson and Winter (1996) note that the buyer group's decision to restrict the number of suppliers they deal with may be good for welfare where it reduces excess entry.

The key difference between our paper and those of Gans and King (2002) and Matthewson and Winter (1996) is that in their papers buyers are, in effect, final consumers. In contrast, we model buyers specifically as downstream firms and consider how buyer mergers affect welfare in each local market as well as the whole

\footnotetext{
${ }^{22}$ This is in contrast to the case where the large buyer has no first mover advantage and purchases on the spot market. This would allow both suppliers to produce at efficient levels and so all buyers would be supplied at $\mathrm{c}\left(\mathrm{Q}^{*}\right)$ and welfare would be higher.
} 
industry. Buyer demands are therefore interdependent, being linked through the procurement market.

\subsection{Buyer mergers}

Chen (2003) considers the incentive for a retailer to enter one or more local markets. To set the scene, Chen (2003) assumes that a monopoly supplier sells to a dominant downstream firm, D, and a downstream fringe. The supplier first announces a price for the fringe and then strikes an efficient bargain with D, taking the fringe price and D's bargaining power as given. Finally, D and fringe firms compete to sell to final consumers.

The key to the model is D's bargaining power with the monopoly supplier. Chen assumes that $\mathrm{D}$ takes a share, $\gamma$, of the surplus generated by its deal with the monopolist. The monopolist earns profit from two sources - its bargain with D and its sales to fringe firms. As $\gamma$ increases, the monopolist's share of the spoils from dealing with $\mathrm{D}$ declines and so, at the margin, sales to fringe firms become more important. This induces the monopolist to lower the input price it offers fringe firms.

Prior to the game there are several downstream markets consisting only of fringe firms. At the start of the game, D can choose how many markets to enter (this is similar to our buyer merger stage) and $\gamma$ is increasing with the number of markets in which $\mathrm{D}$ is active (e.g. because this makes backwards integration more profitable). This means that D faces a trade off: as $\gamma$ increases D obtains a larger share of the bargaining pie but faces greater competition from the fringe (which reduces the size of the bargaining pie). As a result, D may limit the number of markets in which it is active to ensure that its bargaining power is not too high.

The results in Chen (2003) results are almost directly opposite to those in our paper: the 'merger' (i.e. taking a presence in a local market where previously there were fringe players only) lowers rivals' costs and buyer 'mergers' may be profitable only up to a point (whereas in our paper mergers become more and more profitable as $r$ increases). One key difference in the two papers is the nature of upstream competition. In Chen (2003) there is no upstream competition, while in our paper upstream competition is intense.

This begs the question: what happens with intermediate forms of upstream competition in our model? With weaker forms of upstream competition, the nature of the cost curves would be the key to deriving a waterbed result. ${ }^{23}$

\footnotetext{
${ }^{23}$ For example, suppose that $\mathrm{M}_{1}$ is the only supplier. Assume that, at stage $2, \mathrm{M}_{1}$ strikes an efficient bargain with $\mathrm{R}$ (in which $\mathrm{R}$ is supplied at marginal cost and a fixed fee is paid depending on relative bargaining strengths). Suppose that the merger enhances $\mathrm{R}$ 's bargaining power with $\mathrm{M}_{1}$ (e.g. because it makes self supply more credible). Suppose also that dealing with $\mathrm{R}$ adds incremental surplus (i.e. $\mathrm{M}_{1}$ 's fall back option of selling only through independent stores is worse than when it sells through $\mathrm{R}$ as well) and that $\mathrm{R}$ cannot contract with $\mathrm{M}_{1}$ to prevent a spot market price being set at stage 3 . Under these conditions, the merger may lead to a fall in spot market demand and a higher spot market price where $M_{l}$ 's marginal cost rises sufficiently steeply as output declines. Thus, even without upstream competition, a waterbed effect could occur.
} 
Our paper also differs from a strand of recent contributions that address how mergers among buyers may be profitable through affecting the merged entity's share of the incremental surplus resulting from an efficient bargain with a monopoly supplier. For example, Chipty and Snyder (1999), Inderst and Wey (2003), and Raskovich (2003) focus on buyers that operate in independent markets (so there is no incentive to merge in order to enhance downstream market power) and show that the profitability of a merger depends on whether the 'gross surplus function' is concave or not. ${ }^{24}$

Dobson and Waterson (1997) take a different approach to modelling buyer power and buyer mergers. In their model, a monopoly supplier sells to symmetric, differentiated retailers in a single downstream market. A retailer's input price is determined by a Nash bargain struck with the supplier (there are no fixed fees). An increase in buyer power is modelled by a reduction in the number of retailers (i.e. a buyer merger 'destroys' a buyer). This typically reduces the supplier's bargaining power with a retailer by reducing its fall back option (i.e. the profit available from selling to other retailers). However, even though a decline in the number of retailers lowers the input price, it also raises market power in the retail market. Thus, unless downstream competition is very intense (almost perfect), buyer mergers harm welfare because the market power effect dominates and consumers pay more. ${ }^{25}$

In our setting, buyer mergers may also harm welfare, although for a different reason their effect in the procurement market. Our model differs from Dobson and Waterson (1997) in three key respects. First, the merger does not 'destroy' a retailer so that the total number of stores remains unchanged after the merger - this allows us to model a buyer merger that does not directly increase downstream seller power. Second, when a merger destroys a firm, this begs the question of whether the merger would be profitable. In our paper, mergers are always profitable (Dobson and Waterson (1997) do not address this issue). Third, we have competing suppliers upstream.

\section{Concluding remarks - policy implications}

We have demonstrated that a profitable downstream merger may lower the merged entity's input price, raise that of its rivals and leave consumers worse off. This waterbed effect is very different from the unilateral and co-ordinated effects usually considered in horizontal merger analysis. The harm arises from a buyer power effect as opposed to a direct increase in seller market power.

Furthermore, we have proved the striking result that with linear demand all mergers involving a powerful buyer harm overall welfare even though the merger leads to efficiencies that substantially increase output by the merged entity. With more general concave demand, mergers harm welfare after a point. The more profitable the

\footnotetext{
${ }^{24}$ The intuition is as follows. Suppose that a monopoly supplier, M, deals with $\mathrm{Z}$ identical buyers simultaneously. Each bargain struck is efficient and, taking other deals as being agreed at their equilibrium values, maximises the extra surplus generated by striking the deal. Denote the latter 'incremental' surplus, $S_{1} . S_{1}$ is shared between $M$ and the relevant buyer according to some fixed rule (e.g. they get half each). Now suppose that $\mathrm{z} \leq \mathrm{Z}$ buyers merge. Denote the incremental surplus available from M's deal with the merged entity as $S_{z}$. Broadly speaking, a concave surplus function means that $S_{z} / z>S_{1}$. Thus it is more profitable for $z$ buyers to merge than to remain independent (for a given incremental surplus sharing rule).

${ }^{25}$ von Ungern-Sternberg (1996) obtains a similar result.
} 
merger, the more likely it is to harm to welfare (and our suspicion is that most mergers harm welfare in this setting).

In policy debates, the concern with buyer power created by mergers is often that lower prices will not be passed on due to the simultaneous creation of seller power (e.g. Dobson and Waterson (1997)) or that buyer power would adversely affect upstream incentives to invest (e.g. CC (2003)). In each case, a case by case analysis is required as buyer power may have beneficial or anti-competitive effects. ${ }^{26}$ This paper presents a different potential concern that a buyer merger that is pursued in order to pursue input price reductions can have an adverse side effect of raising rival's costs.

Our paper was motivated by the use of the waterbed theory in two recent merger assessments in the UK where the argument was put forward that, as a powerful buyer secures a better deal from its suppliers, these suppliers make up lost profits from weak buyers by charging them more. ${ }^{27}$ This paper provides a theoretical grounding for the assertion that a buyer merger could lower the buyer's input price and lead to other buyers paying more. However, the mechanism is not that a supplier makes up lost profits from weaker buyers. Rather, the buyer merger enhances the supplier's market power over weaker buyers.

The waterbed result was driven by the feature that when a buyer is taken out of the spot market, demand falls and this leads to higher spot prices. We provided a specific model which demonstrates this effect and how welfare may decline as a result. We then explained that this result is not highly sensitive to most assumptions. The key assumption is that average and/or marginal costs increase sufficiently as output declines in the spot market.

The waterbed effect is therefore a theoretical possibility that should not be dismissed. Where it does exist, mergers are particularly profitable and the resulting welfare effects may well be negative.

In terms of policy, there are two clear messages. First, before citing waterbed effects as a reason for blocking a merger, competition authorities should specify a coherent model, supported by the facts, which explains how a buyer merger gives rise to a situation where suppliers are willing and able to charge other buyers a higher price than prior to the merger. In short, authorities must address the question: if suppliers can charge higher prices to the weaker buyers after the merger, why were they not charging these prices before the merger? ${ }^{28}$

\footnotetext{
${ }^{26}$ See Dobson and Waterson (1999). Note also recent contributions by Inderst and Wey (2002) who show that innovation may increase as a result of buyer power while Inderst and Shaffer (2004) provide a model in which retail mergers may lead to single sourcing which adversely affects product variety.

${ }^{27}$ In a UK context, the CC included this type of waterbed theory in its report into prospective mergers in the private health care market and the supermarket sector (see CC (2000), CC (2003) and section 1.1 above). In the latter case, the balance of survey evidence suggested that waterbed effects were unlikely to occur, although a significant minority of responses thought otherwise, (CC, 2003). In a European context, waterbed effects have been recognised too (see for example, (Faull and Nikpay, 1999, paragraph 6.325).

${ }^{28}$ The CC did not address this question in CC (2000) and CC (2003).
} 
Second, there are risks involved when a buyer merger in an intermediate market is considered under separate merger regimes. For example, suppose that there are national downstream markets and an international procurement market. To give the national authority scope to address the downstream issues and then give the European Commission scope to address the procurement issues could make it less likely that the interactions between the two levels are fully taken into account. ${ }^{29}$

\footnotetext{
${ }^{29}$ In the supermarket retail merger Carrefour/Promodes, the European Commission (2000) referred the analysis of the effect of the merger to the respective national authorities (France and Spain). This is not to argue that the waterbed effect had any relevance in this merger. Rather this is an example of how separate merger regimes may consider different aspects of a merger.
} 


\section{$\underline{\text { References }}$}

Chen, Z. (2003), 'Dominant Retailers and the Countervailing-Power Hypothesis', Rand Journal of Economics, 34(4), 612-625.

Chipty, T. and C. M. Snyder (1999), 'The Role of Firm Size in Bilateral Bargaining: A Study of the Cable Television Industry', The Review of Economics and Statistics, 81(2): 326-340.

Competition Commission (2000), British United Provident Association Limited and Community Hospitals Group plc: A report on the proposed merger; and British United Provident Association Limited, Salomon International LLC and Community Hospitals Group plc; and Salomon International LLC and Community Hospitals Group plc: A report on the existing mergers, Cm 5003, HMSO.

Competition Commission (2003), Safeway plc and Asda Group Limited (owned by Wal-Mart Stores Inc); Wm Morrison Supermarkets PLC; J Sainsbury plc; and Tesco plc, Cm5950, HMSO.

Dobson, P. W. and M. Waterson (1997), 'Countervailing Power and Consumer Prices', Economic Journal 107, 418-430.

Dobson, P. W. and M. Waterson (1999), 'Retailer Power: Recent Developments and Policy Implications, Economic Policy, 28, 133-164.

European Commission (2000), Commission Decision COMP/M.1664, Carrefour/Promodes, O. J. (C 164) 5.

Farrell, J. and C. Shapiro (1990), 'Horizontal Mergers: An Equilibrium Analysis', American Economic Review, 80, 107-26.

Faull, J. and A. Nikpay, eds, (1999), The EC Law of Competition, Oxford University Press, Oxford.

Gans, J. S. and S. P. King (2002), 'Exclusionary Contracts and Competition for Large Buyers', International Journal of Industrial Organization, 20, 1363-1381.

Inderst, R. and G. Shaffer (2004), 'Retail Mergers, Buyer Power and Product Variety, mimeograph.

Inderst, R. and C. Wey (2003), Buyer Power and Supplier Incentives, CEPR Discussion Paper No. 3547, London.

Inderst, R. and C. Wey (2003), 'Bargaining, Mergers, and Technology Choice in Bilaterally Oligopolistic Industries', Rand Journal of Economics, 34(1), 1-19.

Klemperer, P. (2005), 'Bidding markets', available at http://www.competitioncommission.org.uk/our_role/analysis/bidding_markets.pdf 
Mason, R. (2002), 'Cost-Raising Strategies in a Symmetric, Dynamic Duopoly', The Journal of Industrial Economics, 50(3), 317-335.

Matthewson, F. and R. A. Winter (1996), 'Buyer Groups', International Journal of Industrial Organization, 15, 137-164.

Raskovich, R. (2003), 'Pivotal Buyers and Bargaining Position', The Journal of Industrial Economics, 51(4), 405-426.

Rasmusen, E., J. Ramseyer, and J. Wiley (1991), 'Naked Exclusion', American Economic Review, 81, 1137-1145.

Salop S. C. and D. T. Scheffman (1983), 'Raising rivals' costs', American Economic Review, 73(5), PP 267-271.

von Ungern-Sternberg, T. (1996), 'Countervailing Power Revisited, International Journal of Industrial Organization, 14, 507-520. 


\section{Appendix}

Proof of Proposition 2: When local demand is linear, welfare always declines as a result of the merger.

Suppose in any local market, $j$, inverse demand is:

$$
\mathrm{P}_{\mathrm{j}}=a-b \mathrm{Q}_{\mathrm{j}}(s)
$$

Note that $s$ is a function of $r$. However, to avoid notational clutter, we refer to $s$ instead of $s(r)$. [A1] gives rise to the following Cournot outputs for independents and $\mathrm{R}$ :

$$
\begin{aligned}
& \mathrm{q}_{\mathrm{L}}(s)=(a-s) /(n+1) b \\
& \mathrm{q}_{\mathrm{LR}}(s)=(a-2 s) /(n+1) b \\
& \mathrm{q}_{\mathrm{R}}(s)=(a+(n-1) s) /(n+1) b
\end{aligned}
$$

where, as in the main text, $\mathrm{q}_{\mathrm{L}}(s)$ refers to output by an independent that does not compete with $\mathrm{R}, \mathrm{q}_{\mathrm{LR}}(s)$ refers to output by an independent that does compete with $\mathrm{R}$ and $\mathrm{q}_{\mathrm{R}}(s)$ refers to output by one of R's stores.

We then take the expressions [A2] and [A3] and substitute these values into [3] to give an expression for spot market demand, $\mathrm{Q}_{\mathrm{s}}(s)$.

$$
\mathrm{Q}_{\mathrm{S}}(s)=\{(m-r) n(a-s)+r(n-1)(a-2 s)\} /(n+1) b
$$

Multiplying [A5] by $s$, equating $s \mathrm{Q}_{\mathrm{S}}(s)$ with $F$ and rearranging yields:

$$
(m n+(n-2) r) s^{2}-a(m n-r) s+(n+1) b F=0
$$

The equilibrium spot market price is the lowest root of [A6]. $F$ is assumed low enough such that the above quadratic has two roots for any value of $r$ in the range $1 \leq$ $r \leq m$.

Apply the implicit function rule to [A6] to find $\mathrm{d} s / \mathrm{d} r$ :

$$
\mathrm{d} s / \mathrm{d} r=s(a+(n-2) s) /\{a(m n-r)-2(m n+(n-2) r) s\}
$$

From lemma 1, we know that $\mathrm{d} s / \mathrm{d} r>0$ and hence the denominator of [A7] is positive:

$$
a(m n-r)>2(m n+(n-2) r) s
$$

Since $\mathrm{M}_{1}$ 's marginal cost of production is zero, welfare, $\mathrm{W}_{\mathrm{j}}$ in local market $j$ is the area under the demand curve in the range 0 to $\mathrm{Q}_{\mathrm{j}}$. This equals:

$$
\mathrm{W}_{\mathrm{j}}=1 / 2\left(a+\mathrm{P}_{\mathrm{j}}\right) \mathrm{Q}_{\mathrm{j}}
$$


Let subscript $\mathrm{R}$ denote one of the $r$ markets where $\mathrm{R}$ has a presence and subscript $\mathrm{L}$ denote one of the $(m-r)$ markets where $\mathrm{R}$ does not have a presence:

$$
\mathrm{P}_{\mathrm{R}}=(a+(n-1) s) /(n+1)
$$

$$
\mathrm{Q}_{\mathrm{R}}=(n a-(n-1) s) /(n+1) b
$$

$$
\mathrm{P}_{\mathrm{L}}=(a+n s) /(n+1)
$$

Combining [A9] to [A13] total welfare, $\mathrm{W}$ can be written:

$$
\frac{\left\{a^{2} m n(n+2)-2 a(m n-r) s-\left(m n^{2}-(2 n-1)\right) s^{2}\right\}}{\left\{2 b(n+1)^{2}\right\}}-F
$$

Recall that $s$ is a function of $r$ and note that the denominator does not depend on $r$. This means that the sign of $\mathrm{dW} / \mathrm{d} r$ is determined by the sign of the derivative of the numerator with respect to $r$ :

$$
\begin{aligned}
\text { sign } \mathrm{dW} / \mathrm{d} r=\operatorname{sign} \quad & \left\{2 a s+(2 n-1) s^{2}-2 a(m n-r) \mathrm{d} s / \mathrm{d} r\right. \\
& \left.-2 s\left(m n^{2}-(2 n-1) r\right) \mathrm{d} s / \mathrm{d} r\right\}
\end{aligned}
$$

Substituting [A7] for $\mathrm{d} s / \mathrm{d} r$ and rearranging yields:

$$
\frac{-s^{2}\left\{a(m n(2 n+1)-3 r)+2 m n\left(n^{2}-1\right) s\right\}}{\{a(m n-r)-2(m n+(n-2) r) s\}}
$$

From [A8] and noting that $1 \leq r \leq m$ and $n \geq 2$, the sign of [A16] is negative. Thus total welfare is decreasing in $r$. $Q E D$.

Lemma 3: When local demand $\mathrm{P}(\mathrm{Q})$ is concave, i.e. $\mathrm{P}^{\prime}(\mathrm{Q})<0$ and $\mathrm{P}$ ', $(\mathrm{Q})<0$, a sufficient condition for welfare to decline as a result of $\mathrm{R}$ purchasing an additional store in a target market is: $\quad(n-1) \mathrm{d} s^{b}(r) / \mathrm{d} r>s^{b}(r)$

Proof. First note that with concave demand and constant marginal costs, output in a local market is decreasing in the sum of the marginal costs of the stores supplying that market as we demonstrate below.

Given Cournot competition among $n$ stores with constant marginal cost, $v_{i}$, facing a market demand curve $\mathrm{P}(\mathrm{Q})$, the first order condition for store $i(i=1,2, \ldots, n)$ yields:

$$
\mathrm{P}(\mathrm{Q})-\mathrm{P}^{\prime}(\mathrm{Q}) \mathrm{q}_{i}-\mathrm{v}_{i}=0 \text {. }
$$

Summing for all stores and rearranging yields: 


$$
n \mathrm{P}(\mathrm{Q})+\mathrm{P}^{\prime}(\mathrm{Q}) \mathrm{Q}-\Sigma_{\forall i} \mathrm{U}_{i}=0
$$

Since $\mathrm{P}^{\prime}(\mathrm{Q})<0$ and $\mathrm{P}^{\prime}(\mathrm{Q}) \leq 0$, by the implicit function rule, $\mathrm{dQ} / \mathrm{d}\left(\Sigma_{\forall i} \mathrm{v}_{i}\right)<0$.

When R purchases an additional store, that store's input price falls to zero from $s^{b}(r)$. The $(n-1)$ other stores face a rise in their input price equal to $\mathrm{d} s^{b}(r) / \mathrm{d} r$. If the latter effect dominates the former then the sum of marginal costs increase and so output in the target market falls. This is a sufficient condition for the merger to harm welfare. $Q E D$.

Lemma 4: $\mathrm{d}^{2} \mathrm{~W}(r) / \mathrm{d} r^{2}<0$. In other words, the more stores that $\mathrm{R}$ owns, the more harmful (or less beneficial) is a further merger.

The proof has the following stages.

Stage 1: The expression

$$
(n-1) \mathrm{d} s^{b}(r) / \mathrm{d} r-s^{b}(r)
$$

is increasing in $r$.

Proof of stage 1. From [6] and [7], [A19], $\mathrm{d} s^{b}(r) / \mathrm{dr}$ is:

[A20] $s^{b}(r)\left\{n \mathrm{q}_{\mathrm{L}}\left(s^{b}(r)\right)-(n-1) \mathrm{q}_{\mathrm{LR}}\left(s^{b}(r)\right)\right\} /\left(1-\eta\left(s^{b}(r)\right)\right) \mathrm{Q}_{\mathrm{S}}\left(s^{b}(r)\right)$

Substituting [A20] into [A19] and rearranging (and dropping the arguments to avoid clutter) yields:

$$
(1 / m)\left(1-(n-1) \mathrm{q}_{\mathrm{LR}} / n \mathrm{q}_{\mathrm{L}}\right)\{\mathrm{r}+(n-1) /(1-\eta)\}-1
$$

By inspection, [A21] is increasing in $r$. First consider $\mathrm{q}_{\mathrm{LR}} / \mathrm{q}_{\mathrm{L}}$. As $r$ increases, so does $s^{b}$. Both $\mathrm{q}_{\mathrm{LR}}$ and $\mathrm{q}_{\mathrm{L}}$ fall but $\mathrm{q}_{\mathrm{LR}}$ falls more quickly because output is more sensitive to a rise in the spot price in markets where independents compete with $\mathrm{R}$ as opposed to competing only with other independents. As $\mathrm{q}_{\mathrm{LR}} / \mathrm{q}_{\mathrm{L}}$ falls the term in bold brackets increases.

Now consider terms in curly brackets. The first term is clearly increasing in $r$. Furthermore, as $\mathrm{r}$ increases, spot market demand becomes more elastic. Thus, $\eta$ increases and the expression $(n-1) /(1-\eta)$ goes up. $Q E D$.

Stage 2. We now complete the proof of lemma 4. Since [A19] is increasing in $r$, this means that as $r$ goes up, the raising rivals' cost effect becomes stronger. The contribution to welfare from the target market decreases (i.e. becomes less positive or, when [8] holds, becomes more negative). Further, the contribution to overall welfare from markets other than the target market is more negative (because output in those markets declines by a greater amount). $Q E D$. 


\section{Proposition 3: If local demand is of the form:}

$$
\mathbf{P}_{j}(s)=a-b \mathbf{Q}_{j}(s)^{k}
$$

where $k \geq 1$, then after a point (i.e. for $r>r_{0}$, where $1 \leq r_{0}<r \leq m$ ) a merger harms welfare.

From [A22], Cournot output in a local market where R does not compete is:

$$
\mathrm{Q}_{\mathrm{L}}(s)=\{(n a-n s) /(n+k) b\}^{1 / k}
$$

and where $\mathrm{R}$ has a presence:

$$
\mathrm{Q}_{\mathrm{R}}(s)=\{(n a-(n-1) s) /(n+k) b\}^{1 / k}
$$

An independent that competes with $\mathrm{R}$ has output:

$$
\mathrm{q}_{\mathrm{LR}}=\gamma_{\mathrm{LR}}(s) \mathrm{Q}_{\mathrm{R}}(s)
$$

where $\mathrm{Q}_{\mathrm{R}}(s)$ is total output in that market and $\gamma_{\mathrm{LR}}(s)$ is the independent's market share:

$$
\gamma_{\mathrm{LR}}(s)=(1 / k)(k a-(k+1) s) /(n a-(n-1) s)<1 / n
$$

Since $\mathrm{R}$ has a lower input price than any store with which it competes, it must be the case that $\gamma_{\mathrm{LR}}(s)<1 / n$.

Suppose that $\mathrm{R}$ has no stores at all so that all purchases are made on the spot market. We can think of this as $r=0 .{ }^{30}$ In this case total output (i.e. summed across all $m$ markets) is the same as spot market output:

$$
m\left\{\left(n a-n s_{r=0}\right) /(n+k) b\right\}^{1 / k}
$$

As before, assume that competition among suppliers means that the spot market price is the lowest that allows one manufacturer to cover its fixed cost:

$$
s_{r=0} m\left\{\left(n a-n s_{r=0}\right) /(n+k) b\right\}^{1 / k}=F
$$

Now suppose that $r=m$ so that $\mathrm{R}$ purchases as many stores as possible at stage 1 (we would expect this as R's profits are increasing in $r$ ). In this case spot market output is:

[A28]

$$
m(n-1) \gamma_{\mathrm{LR}}\left(s_{r=m}\right)\left\{\left(n a-(n-1) s_{r=m}\right) /(n+k) b\right\}^{1 / k}
$$

Thus:

\footnotetext{
${ }^{30}$ Even though we have assumed $r \geq 1$ in the main text nothing turns on this assumption. By setting $r=$ 0 we remove stage 1 of the game so $\mathrm{R}$ does not exist and there is no buyer power.
} 


$$
s_{r=m} m(n-1) \gamma_{\mathrm{LR}}\left(s_{r=m}\right)\left\{\left(n a-(n-1) s_{r=m}\right) /(n+k) b\right\}^{1 / k}=F
$$

Combining [A27] and [A29] we have:

$$
s_{r=0}\left(n a-n s_{r=0}\right)^{1 / k}=s_{r=m}(n-1) \gamma_{\mathrm{LR}}\left(s_{r=m}\right)\left(n a-(n-1) s_{r=m}\right)^{1 / k}
$$

Note that if total output is the same when $r=0$ and when $r=m$, it must be the case that the sum of marginal costs in each local market is the same:

$$
n s_{r=0}=(n-1) s_{r=m}
$$

However, if [A31] holds, the right hand side of [A30] is smaller than the left hand side (from [A25]). To restore the balance we require that:

$$
n s_{r=0}<(n-1) s_{r=m}
$$

since the left hand side of [A30] is increasing in $s_{r=0}$. To see this take the natural logarithm of the left hand side of [A30] and differentiate with respect to $s_{r=0}$. This yields:

$$
1 / s_{r=0}-1 / k\left(a-s_{r=0}\right)
$$

Thus the left hand side of [A30] is increasing in $s_{r=0}$ if:

$$
k a-(k+1) s_{r=0}>0
$$

which surely holds from [A25].

From [A32] the sum of marginal costs is lower and hence output higher when $r=0$ than when $r=m$. Since all local markets are identical at these extremes, $\mathrm{W}(r=m)<$ $\mathrm{W}(r=0)$.

From lemma 4 we know that as $r$ increases welfare either increases more slowly or declines more quickly (although we have focused on $r$ in the range $1 \leq r \leq m$, it is straightforward to see that proposition 5 applies for $0 \leq r \leq m)$. Therefore, even if welfare initially increases in $r$, eventually we must reach some point, $r_{0}$, where welfare starts to decrease with $r$ to ensure that $\mathrm{W}(r=m)<\mathrm{W}(r=0)$. $Q E D$. 